Anita Acai, McMASTER UNIVERSITY, acaia@mcmaster.ca Arshad Ahmad, McMASTER UNIVERSITY, arshad@mcmaster.ca Nancy Fenton, McMASTER UNIVERSITY, fentonn@mcmaster.ca Leah Graystone, McMASTER UNIVERSITY, leahgraystone@allergen-nce.ca Keegan Phillips, McMASTER UNIVERSITY, phillk1@mcmaster.ca Ron Smith, CONCORDIA UNIVERSITY, ronsmith154@bell.net

Denise Stockley, QUEEN'S UNIVERSITY, stockley@queensu.ca

\title{
The 3M National Teaching Fellowship: A High-Impact Community of Practice in Higher Education
}

\begin{abstract}
The $3 \mathrm{M}$ National Teaching Fellowship is a national teaching award program that has recognized over 300 teachers at more than 80 Canadian universities for their teaching excellence and outstanding educational leadership. Despite its rich, 30 plus-year history, its impact has remained largely anecdotal. In this study, we build on Hannah and Lester's (2009) original, multilevel approach that looks at interactions between the individual, network, and systems levels to explore the impact of the $3 \mathrm{M}$ National Teaching Fellowship program on furthering and enriching teaching and learning in higher education. Through the analysis of a large collection of program artefacts corroborated with in-depth interviews with 11 fellows (key informants), we were able to gain a deeper understanding of the ways in which the program has had impact at the individual (micro), departmental (meso), institutional (macro), and national/international (mega) levels. In this article, we outline our scholarly exploration of the program's influence and explore its role as a high-impact community of practice in higher education.
\end{abstract}

\section{KEYWORDS}

teaching, leadership, award, fellowship, impact

\section{INTRODUCTION}

In 1985, the Society of Teaching and Learning in Higher Education (STLHE) partnered with $3 \mathrm{M}$ Canada to create the $3 \mathrm{M}$ National Teaching Fellowship (3MNTF). This unique fellowship program, designed to celebrate teaching excellence and educational leadership in all disciplines, has evolved into one of the most successful public-private partnerships in Canada to date (Ahmad, Stockley, \& Moore, 2013). Since the first cohort of fellows was announced in 1986, over 300 teachers at more than 80 Canadian universities have been recognized for their contributions to higher education and invited to join the fellowship (STLHE, n.d.).

A hallmark of the $3 \mathrm{MNTF}$ program is its dual focus on teaching excellence and educational leadership (Ahmad et al., 2013). As part of the nomination process, the nominator, working with the nominee, puts together a teaching portfolio that provides evidence of the nominee's accomplishments in CC-BY License 4.0 This is an Open Access article distributed under the terms of the Creative Commons - 
both areas. Ahmad et al. (2013) provide the following examples of excellence in teaching and educational leadership, which are weighted equally during the selection process (p. 84):

Examples of teaching excellence include the candidate's philosophy of teaching, teaching strategies used to support the philosophy, teaching awards and recognition, student ratings, course development, letters of support and other related evidence [e.g., work related to the Scholarship of Teaching and Learning]. Examples of leadership evidence include the candidate's statement of what leadership in teaching excellence means and how it is accomplished; this is supported by actual contributions including workshops on teaching and learning, mentorship, research on teaching, and impact on educational development with the institution and beyond.

While these examples have been recognized by institutional and external groups to have achieved excellence, the selection committee spends three full days discriminating whether the candidates meet the threshold deserving of national recognition. Most dossiers meet the stated criteria; however, the six adjudicators must come to a consensus as to which nominations display excellence at a national level. Up to 10 postsecondary teachers ${ }^{1}$ are invited to join the fellowship each year. Successful nominees are personally contacted by the program coordinator and announced publicly in Maclean's, Canada's national weekly current affairs magazine, and at the annual STLHE conference in June, where fellows are officially recognized and celebrated. A second, key component of the award is a four-day scholarly retreat for new fellows, currently held in Montebello, Québec and previously in Banff, Alberta. Discussion topics and how time will be spent are largely left up to the fellows to define, thus allowing for free-flowing dialogue about important educational issues and paving the way for relationships and leadership initiatives that often extend well beyond the retreat.

Those close to the $3 \mathrm{MNTF}$ program are convinced that it has garnered both a national and international reputation, even though its impact has remained largely anecdotal through the program's history. More recently, however, perspectives emerging from a national survey (Ahmad, Stockley, Smith, \& Hastings Truelove, 2017), as well as a number of focus groups, including educational developers, administrators, and others, provide additional evidence of the fellowship's impact (Smith et al., 2017). In addition, a Higher Education Research and Development Society of Australasia guidebook on measuring impact features the $3 \mathrm{MNTF}$ program as one of its two case studies, thereby adding to this scholarship (Ahmad et al., 2018).

Building on this work, we provide additional scholarly evidence to gain a deeper understanding of the levels at which impact occurs in one of Canada's most prestigious national teaching award programs. We do so by building on Hannah and Lester's (2009) original, multilevel approach that looks at interactions between the individual (micro), network (meso), and systems (macro) levels, thereby allowing us to deepen our understanding of impact. To strengthen our analysis at each of these levels, we adopt theoretical lenses of self-authorship (Baxter Magolda, 2007) and significant networks that give rise to communities of practice (Mårtensson \& Roxå, 2015; Wenger, 1998).

\section{Defining and examining impact}

Although impact is a term that most people understand, it remains challenging to operationalize from a research standpoint. A useful way to begin thinking about it is in the context of identifying and 
evaluating change (Streatfield \& Markless, 2009). Given that change can occur on a trajectory from small to large scale, Hannah and Lester's (2009) micro-meso-macro framework is particularly useful to examine the impact of educational programs as it considers the different levels at which impact can occur. Adapting this framework to impact analysis of teaching and learning initiatives, scholars such as Mårtensson and Roxå (2015) define micro as impact occurring at the individual level, meso at the departmental level, and macro at the institutional level. Simmons (2016) also adds a fourth level, mega, which refers to impact at the provincial and national levels. In the context of a teaching award program such as the $3 \mathrm{MNTF}$, individual impact may manifest as developments in a teacher's personal or professional identities while departmental and institutional impact can be evidenced by changes in the policies, practices, and institutional values that inform teaching and learning at a broader level. These policies, practices, and values are further extended to higher education institutions as a broader collective when considering provincial and national impact, which could presumably extend to shift values at a broader, societal level, sometimes crossing national boundaries.

\section{Educational leadership: From individuals to networks}

Teaching excellence is an important criterion of the 3MNTF; however, the program is distinguished from other teaching award programs because of its emphasis on educational leadership (Ahmad et al., 2013). Fellows are not only excellent teachers, but they are also agents of change both within and beyond their institutions.

Given that there is no "one-size-fits-all" definition of educational leadership, there are a multitude of ways in which it can be enacted (Yukl, 2002). Faculty and staff may serve as role models, mentors, advocates, guardians (e.g., of standards of scholarship and academic values), acquisitors (e.g., of grants, resources, research students, and the like), and ambassadors (Macfarlane, 2011). Educational leadership begins at the level of the individual, and it is often a transformative process that takes place gradually over the span of one's career. In other words, one is not "born" an educational leader. Baxter Magolda (2007) offers a useful way of considering this topic in her theory of self-authorship, which is defined as "the internal capacity to define one's own belief system, identity, and relationships" (p. 69). Although self-authorship was originally considered in the context of students' development as they progressed through higher education, it is equally useful in considering faculty leadership development over the course of their career.

For sustainable improvements in teaching and learning to occur, it is necessary for educational leadership to move beyond the level of the individual leader. Specifically, it is necessary to have "a leadership that engages with, supports, and coordinates development in local collegial contextsdepartments, teaching teams, or programme teachers - as well as horizontally and vertically across disciplines and programs” (Graham, 2012 as cited in Mårtensson \& Roxå, 2015, p. 2). Such leaders, termed "local-level leaders," serve as mediators between local programmatic and/or departmental needs and broader institutional mandates, while also acting as individuals that other teachers can talk to and take advice from in matters concerning teaching. Mårtensson and Roxå (2015) also consider the related concept of significant networks, which gives rise to the idea that educational leadership can be facilitated by the formation of communities of practice (Wenger, 1998). Such networks allow individuals with shared goals and values to come together to work towards a common cause-the fellowship, for example, shares an ethos to advance of teaching and learning in higher education. 


\section{METHODOLOGY}

In addition to gathering additional scholarly evidence of the impact of the $3 \mathrm{MNTF}$ program, we also sought to gain a deeper understanding of the levels at which this impact occurs. For this purpose, we selected a version of Hannah and Lester's (2009) micro-meso-macro model that has been adapted to the context of teaching and learning initiatives and includes four levels: micro (individual), meso (departmental), macro (institutional), and mega (provincial and national; Mårtensson \& Rox5., 2015; Simmons, 2016). We retained the original definitions for micro, meso, macro, and mega with one modification: When considering impact at the mega level, we chose to examine national and international impact rather than provincial and national impact because this is consistent with the scope of the program. Thus, in our research, we sought to examine the impact of the 3MNTF program at the individual (micro), departmental (meso), institutional (macro), and national/international (mega) levels.

\section{Artefacts}

Artefacts are overt, observable behaviours or objects that serve as "windows" into organizational culture (Schein, 2004). They can serve as tangible examples of the impact that a program has had at various levels, particularly in cases where other impact metrics are not available and impact assessment must be done retrospectively. The 3MNTF program's rich history had enabled the collection of 32 categories of artefacts, including book publications, final reports from the program coordinator, photographs, press releases, publicity binders, press releases, terms of reference, and documents from the Council of 3M National Teaching Fellows (hereafter referred to as the $3 \mathrm{M}$ Council), and more. Part of our challenge was to determine how to go about analyzing such a large collection of items. We decided to corroborate our analysis of program artefacts with in-depth interviews of key informants: fellows who had maintained a high degree of involvement with the program and could therefore contextualize the $3 \mathrm{MNTF}$ program and its artefacts within our broader impact framework. These fellows were all current or former faculty members at postsecondary institutions across Canada and had held one or more leadership roles within the $3 \mathrm{MNTF}$ program. Examples include members of the fellowship's selection committee, facilitators of the awards retreat, and elected fellows serving on the $3 \mathrm{M}$ Council or STLHE board.

\section{Interviews}

We purposively recruited and contacted 20 fellows via email and provided them with information about the study, seeking consent to participate in an in-depth interview exploring their thoughts on the meaning of the artefacts described above, as well as their beliefs, values, and underlying assumptions about the $3 \mathrm{MNTF}$ program and teaching and learning in higher education. Interviews were semistructured and conducted by telephone by one of two researchers, lasting approximately 60 minutes each. All interviews were audio recorded and subsequently transcribed. This study was approved by the McMaster University Research Ethics Board (MREB 2015-113).

Interview data were analyzed using thematic analysis (Miles \& Huberman, 1994), undertaken by the original interviewers and two additional researchers. Thematic analysis involved the creation and application of codes to the data resulting in a theme-code set, developed by the interviewers and coders, 
based on the review and preliminary interpretations of all interview transcripts. In this study, coding of the interview transcripts involved reading and open-coding discrete units of text to support individual codes found in the theme code set (Miles \& Huberman, 1994). An inter-rater reliability exercise was undertaken between all four independent coders to ensure that the theme code set was both reliable and systematically refined, with each independently coding the same interview transcript. After reaching agreement, a revised theme code set was developed through discussion of meaning and interpretation of codes. Guided by Barbour (2001), from an epistemological perspective, we placed a high degree of value in the content of disagreements and resulting insights that lead to coding refinement and alternative interpretations, versus the actual reliability score itself. Such an approach lends itself to thoroughness of data interrogation, and improved transparency of the systematic process.

\section{RESULTS}

Of the 20 key informants we contacted as part of this study, 12 participated in an in-depth interview. Participant demographics are provided in Table 1. During the data collection process, two interviews were lost because of technical difficulties with the recording device. However, one of these interviews was accompanied with a set of notes that had been sent to the research team by the interviewee, thereby resulting in a total of 11 key informant interviews.

Table 1. Participant demographics

\begin{tabular}{ll}
\hline GENDER & Male: 6 \\
& Female: 5 \\
\hline COHORT & 1986-1990: 3 \\
& $1996-2000: 2$ \\
& $2001-2005: 3$ \\
& $2006-2010: 3$ \\
\hline DISCIPLINE & Health sciences: 2 \\
& Humanities: 6 \\
& Social sciences: 3 \\
\hline INSTITUTION TYPE & Undergraduate: 4 \\
& Comprehensive: 5 \\
& Medical doctoral: 2 \\
\hline GEOGRAPHY & Eastern Canada: 5 \\
& Central Canada: 5 \\
& Western Canada: 1
\end{tabular}

\section{Organizational culture of the 3MNTF program}

Fellows described the $3 \mathrm{MNTF}$ program as a "true fellowship" rooted in deep personal and professional relationships or as being "marked by collegiality and a celebration of ... differences," meaning that although fellows came from many different walks of life, they remained united by their shared passion for teaching and leadership in higher education: 
I think of distinction within variety. I think of excellence within variety. I think of a breaking down of paradigms and individuals who rise above the paradigms. I think in terms of siblinghood... of friendship. I think in terms of a commitment and an essence of believing that ... being teachers is one of the most important things that we can do.

The idea of a true fellowship was further characterized by the symbolism behind being invited to join the fellowship as opposed to receiving a (monetary) prize. One fellow described this invitation as being a "distinct honour ... because you become aware of past recipients of the fellowship who were ready to become fellows and it's quite inspiring to be associated with a group like that." Along similar lines, another fellow described the fellowship as a gateway to new opportunities and relationships that fostered further engagement in the teaching and learning community:

Its not a prize, but a portal... So, not just in other words a capstone award where you get some money and are sent on your way. It's not an award that you get at the end of your career. Rather, it's something that acknowledges your efforts and excellence in teaching, but then initiates you into a lifetime of service.

The strength of the $3 \mathrm{MNTF}$ community was seen to be rooted in the scholarly retreat, which fellows often considered to be one of the first times they felt they could openly share critical and personal issues about teaching and learning with others who shared a similar passion. The range of topics and issues discussed varied tremendously, creating a shared sense of vulnerability that led to further bonding and illustrated the deep personal commitment fellows had to strengthening an ethos that was particular to the fellowship:

I think [the retreat] was one of the most powerful experiences. It was almost the first opportunity where I could speak about my teaching experiences with other colleagues who felt the same way. So, for me it was an opening of souls that met in one place to talk about something that we were all passionate about. And we understood each other.

Fellows felt the most important parts of the retreat were the conversations that took place. These often resulted in the formation of deep personal and professional relationships that extended well beyond the retreat and often catalyzed further projects. One such project was the 2011 "Thank Your Teacher" campaign wherein the cohort reflected on the power of teaching in Canada's national newspaper, the Globe and Mail, by saying thanks to the teachers who changed their lives. They encouraged the public to join them by writing letters to their most influential teachers. Illustrating the power of these stories, an excerpt from a letter read,

I was a high school dropout returning to school for the first time in 10 years. You liked my essay on Heart of Darkness, and you asked me something nobody had ever asked me before, "Have you ever thought about going to university?" Well I did. 


\section{Individual impact (micro level)}

All of the key informants considered their entry into the fellowship to have been a transformational event in their personal and professional lives. On a personal level, the fellowship program recognized and validated their identity as teachers, which some felt was not always valued at their home institutions. It also connected them to other academics who held similar values, thereby helping to foster a sense of purpose and belonging:

In the academy, we feel that we are not in the mainstream... And we feel somewhat... ostracized or at least outliers. So, for me, the [fellowship] told me that there were people out there who believed in what I was doing. And that validation was so important.

In conjunction with its deep personal impact, the fellowship also helped open doors professionally. One example in particular that stood out to us was when a fellow explained how award had played a major role in a promotion to full professor. Another fellow thought her involvement with the program was "without a doubt the most important element of my academic career."

Once invited to the fellowship, key informants reported a renewed sense of confidence in their teaching and leadership abilities and a greater willingness to try new things in both areas. For example, one fellow explained, "[the fellowship] gave me a license to continue to dare to do more and to be more and to risk more in teaching." Other fellows shared similar sentiments with respect to not only the development of their teaching abilities, but also to the growth in confidence to participate in educational leadership initiatives, thus affirming the award's ability to catalyze individual development in both areas:

Since the $3 M$ award, I have worked in various levels of education and leadership, which as well as being a teaching award, the [fellowship] is meant to stimulate and contribute to educational leadership... And so, I take my role as an educational leader seriously. I do as much as I can to live that role in ways that are meaningful and helpful.

The individual impact of the 3MNTF program was further evidenced by fellows' perceptions of the importance of several program artefacts, such as the $3 \mathrm{M}$ ring and oath, conceived in 2009 and incorporated into the awards ceremony during the program's 25th anniversary, and the Postcard project, developed in 2010 to express to the community how the fellowship has made a difference. Fellows felt the $3 \mathrm{M}$ ring and oath symbolized a newfound belonging and unity, while the Postcard project provided them with an opportunity to creatively convey the impact of the award on their lives. One such postcard (Figure 1), decorated with the words "inspired," "visionary," and "generous" read, "To 3M: Reminder [,] I think of you every day, with gratitude.” 


\section{Figure 1. An example of a postcard created by a fellow to commemorate the fellowship's $25^{\text {th }}$ anniversary}

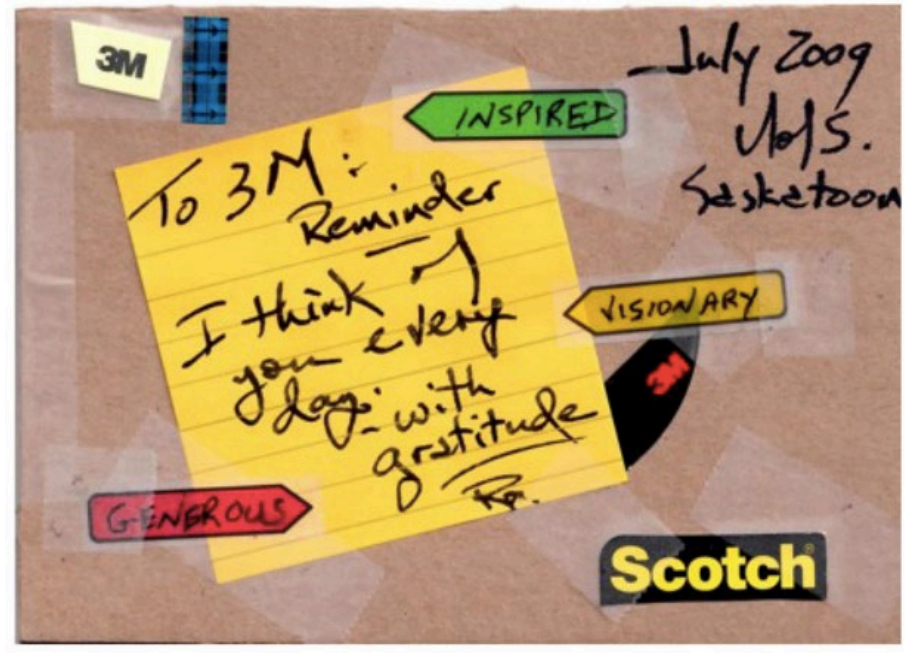

\section{Departmental and institutional impact (meso and macro levels)}

The fellows we interviewed felt their institutions particularly valued the fellowship program. This was often manifested as greater recognition of their educational leadership, including being called upon to inform or lead important institutional initiatives or being given formal leadership positions to help further the cause of teaching and learning in higher education:

To start with administrators, I think they take it seriously... And they will ... call on 3Ms specifically when there's a teaching-related matter happening ... not just because these are people who are good in the classroom, but because they're known for their leadership ability through the award.

Another program artefact, a 2012 survey of 57 fellows by the $3 \mathrm{M}$ Council, revealed that 43 percent of those surveyed were in administrative positions such as departmental chair, associate dean, teaching and learning centre director, associate vice president, and president. Our interview findings supported these results, suggesting that many of these fellows' institutions considered the fellowship as having an impact equivalent to that of other scholarly achievements, which created new pathways to recognize teaching excellence and educational leadership.

The survey also revealed that roughly a quarter of respondents considered themselves to be advocates of teaching and learning in their universities, departments, and faculties. Narrative comments detailing fellows' advocacy efforts were extensive, providing dozens of detailed examples such as "I constantly express the importance of teaching and learning, and how teaching and research are related and synergistic. This is directed to senior management at my university, as well as national bodies." Likewise, in our interviews, fellows provided several instances of how they leveraged their role(s) as educational leaders to promote teaching and learning excellence within their institutions, including, for example, the creation of a new teaching award at their university:

One of my colleagues mentioned that [faculty] was the only faculty at the university that did not have a teaching award. Well, the new Dean was aghast; he could not believe that there was no 
teaching award! And there was an Associate Dean sitting at the table ... and he said, "Look, we just don't have the resources.". .. So, I said, "I'll do it for you."

Fellows also referred to the institutional impact of one of the more prominent program artefacts - articles in a national magazine, Maclean's, which has been making the official announcement of 3M National Teaching Fellows since 2006. In its annual ranking of Canadian universities, read nationally by thousands of prospective students and their families, Maclean's uses the number of 3M National Teaching Fellows at an institution as an indicator of its teaching quality. It also devotes several pages in a special issue announcing a new cohort. As a result, institutions have an even greater (although perhaps not entirely altruistic) incentive to value the award.

Fellows' perceptions on departmental-level impact were mixed compared to their perceptions of its impact at the institutional level. While one fellow felt she was in "such a great department ... that honestly does value and celebrate the accomplishments of [its] colleagues," others did not share this view: "The administration gives it more importance than your colleagues. Colleagues don't [care]." While some departmental contexts appeared to be very positive, others were not, thus promoting jealousy and even competition between colleagues. One fellow told us that her colleagues, "see it as, 'Oh, you are popular with your students." Many others echoed these sentiments, citing preexisting departmental cultures that value research as the gold standard of accomplishment.

Yet, overall, regardless of the varied departmental and institutional cultures, we encountered more examples of the positive impacts of their award than negative ones. As educational leaders, fellows understood that some negative external perceptions were inevitable, but did not allow these to prevent them from championing a cause they deeply believed in:

You have to learn to accept the way people react and keep moving. I mean, the fact that we are $3 M$ fellows, nobody can take that away from us. And I value it. I highly value the designation. I feel very blessed.

Moreover, fellows frequently referenced the strong community that characterized the fellowship program itself as being something that gave them strength, support, and validation when it was needed. This was especially true among those who had experienced negativity surrounding the award at their home institutions:

This for me was very important_I met a whole bunch of people who had similar interests to me that were ... total opposites to what I was experiencing in my own institution... A siblinghood of men and women, a lot of them in the same situation as me but not necessarily talking about the nastiness back home... their support, their talk, their interests [were] tremendous.

\section{National/international impact (mega level)}

In the earlier years of the fellowship, projects and initiatives primarily emerged organically from relationships that had been built within the program. Although these types of grassroots initiatives continue to remain an important part of the fellowship program, it became clear that as more cohorts joined, a more formal organizational structure would leverage the impact of the fellowship on a broader 
scale. This proved to be the case following a national think tank event in 2003, which led to the formation of the $3 \mathrm{M}$ Council. For one participant, this represented a new way to keep fellows across the country connected:

Before, I was an individual teacher doing good things in my classes. And making a difference with the students that I engaged with... When the award happened, I was now part of a council of teachers who were similarly making a difference in the lives of learners. So, it was not just me and my learners anymore. It was a group of us and the potential we had as a group to make post-secondary education better for many learners.

Another fellow commented,

Relationships need a way to grow them, and the STLHE conferences really do that. Since the $3 M$ Council was formed... they have found, or looked for other ways to keep, at least those 3Ms who want to have those connections, together with the reunion dinners every STLHE [conference], email blasts, and that type of thing. I think that helps give a framework, at least.

Over the years, the $3 \mathrm{M}$ Council assumed a role that was central to the broader impact of the fellowship program through the development of several national initiatives to advance teaching and learning in higher education. These included three book publications with contributions from nearly 100 fellows (Figure 2), the Scholarship of Leadership in Education grant to fund collaborative educational leadership initiatives by $3 \mathrm{M}$ fellows, a speakers list of 32 fellows, the aforementioned Postcard project to commemorate the meaning of the fellowship on its 25 th anniversary, and several key partnerships with a number of external organizations. For example, the fellowship program's partnership with Maclean's magazine was seen as the most influential partnership in that it brought "national prominence to excellence in teaching and educational leadership."

Figure 2. Covers of the 3M Council's three book publications: Making a Difference (left), Silences (center), and Students Speak (right)

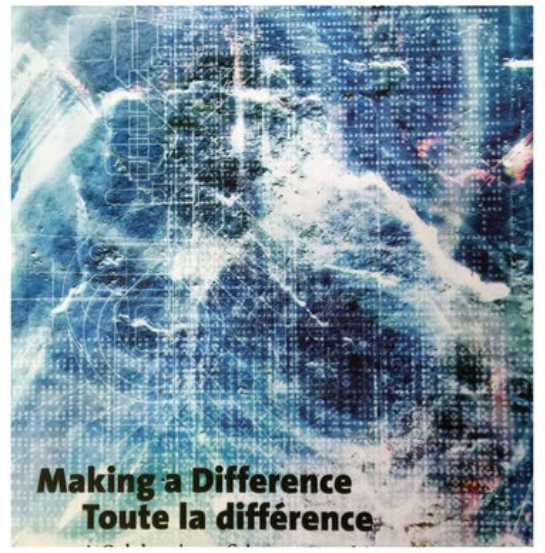

students Lives Transformed by Teachers 
These initiatives, as well as several others emerging through fellows' leadership efforts (e.g., the Positive Pedagogy journal initiated by a fellow at McMaster University, the "Ethical Principles in University Teaching" document that was authored by four fellows and endorsed by 40 others whose names appear on the cover, or the 2011 cohort's "Thank Your Teacher" campaign in the Globe and Mail), served an important role in extending conversations about teaching and learning from within the academy into the public realm. Besides their personal meaning, the tangible artefacts produced through the work of the $3 \mathrm{M}$ Council and other cohort projects were seen by the fellows as mechanisms by which the shared vision of the fellowship was transformed into a message that others could relate to:

[The books] took teaching and learning, and reflection on teaching and learning ... beyond the level of folklore and myth and gave [it] a [recognizable] forum... [that] could engage and inspire other people.

Importantly, the book publications also included the voices of students and colleagues whose lives have been affected by fellows. For example, in Making a Difference, a student testimonial reads,

From the first moment I stepped into her classroom, I could feel something like a spell take hold of me. The classes were about four and a half hours long, yet at the end, many students still lingered. We could hardly wait until the next class. It was like reading a good book. You cannot put it down. One day we started talking about grief and soon were deep into personal stories. She altered the agenda to allow us to spend the rest of the class on the subject of grief and loss. What came about was memorable. Some of the students admitted to never having shared these intense and personal stories with anyone before. In her classes, we talked, we argued, we listened, we laughed and we cried. We were often loud and sometimes very quiet and somber. Through all of this, we learned.

A 2012 3M Council survey described in the previous section showed that over two-thirds of respondents mentored individuals outside of their university. Furthermore, it was common for most of them to be in touch with fellows at their own university and at neighbouring universities (at least once or twice per year). The continuous desire to create and strengthen opportunities for $3 \mathrm{M}$ fellows to make connections across Canada and to build and sustain communities of excellent teachers and educational leaders was expanded with an informal group of teaching fellows from similar award programs in the United States, United Kingdom, Australia, and New Zealand (Figure 3). One fellow recounted this process in their interview:

We were able to create a multinational forum to discuss issues of teaching and learning. As we shared across boundaries, we discovered that we had similar problems and similar challenges. But, we also had sometimes different solutions. So, that was pretty exciting. 


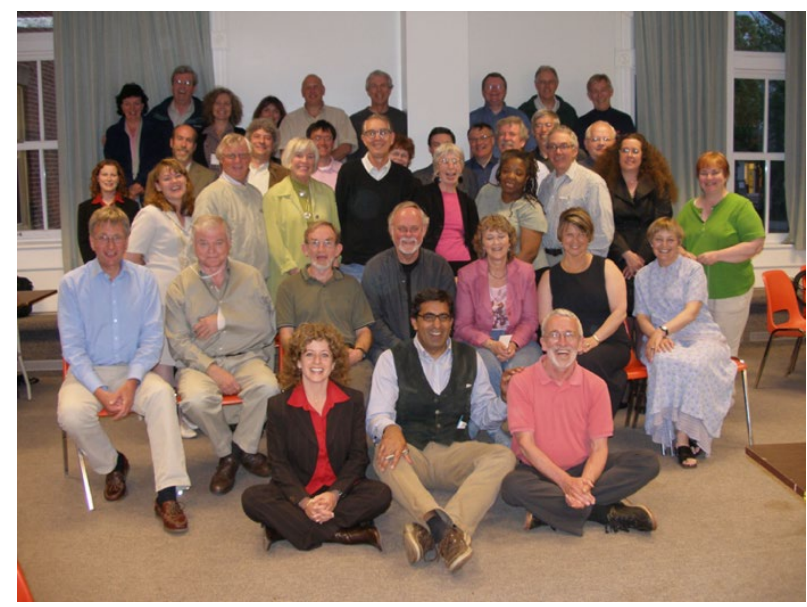

These multinational forums were held in conjunction with national conferences, including the American Association for Higher Education, the STLHE, and the Staff and Educational Development Association, before eventually becoming a regular part of the International Society for the Scholarship of Teaching and Learning. The second Multinational Forum held in Prince Edward Island was one of the largest gatherings, and it created a momentum to sustain meetings that resulted in strengthening lasting networks in other international organizations, including the International Consortium for Educational Development. In 2016 at the House of Lords in England, the International Federation of National Teaching Fellows was officially recognized, with the 3MNTF having played a pivotal role in its development.

Tangible examples of fellows' influence on an international scale can also be found in the 2012 $3 \mathrm{M}$ Council survey, which includes examples of fellows leading teaching and mentoring sessions overseas, participating in professional development opportunities such as international exchanges and retreats, chairing international committees related to teaching and learning, supporting education initiatives in developing countries, presenting at international conferences on teaching and learning, and authoring publications targeting a global audience.

The high standard of the fellowship is also reflected in the criteria that define what counts as evidence of teaching excellence and educational leadership. These criteria have evolved over the years so they represent not only a checklist that nominators can tick off, but also a compelling story about a teacher who is deserving of the highest honour a national recognition can bestow. As mentioned in one of the program artefacts, an essay written by the 3M Program Coordinator in 2008, the selection committee was challenged by the fact that most of the nominees met the stated criteria, which led to the development of "meta" criteria that helped to further differentiate candidates with attributes such as, "creative, authentic, fresh, genuine, authoritative, super energetic, captivating, convincing, versatile, different, innovative, path-finding, way-breaking, pioneering, passionate, transformational, and deep!”

The fellowship program has not only led to an enriched understanding of what counts for teaching effectiveness, but it has also helped to raise standards that demand nominators to support rhetoric with concrete examples of evidence that align with their teaching beliefs and philosophies. The 
criteria and approach used by the fellowship have inspired the creation of many local teaching awards at institutions across Canada and abroad that emulate or borrow from the $3 \mathrm{MNTF}$ criteria. Many consider institutional recognition as the first step to preparing nominees for regional and international awards that ultimately help them qualify to be considered for a 3MNTF. Similarly, international associations from Australia, Ireland, South Africa, and New Zealand have consulted with the $3 \mathrm{M}$ Council to create their own awards.

Finally, one of the more tangible impacts of the fellowship was the creation of the $3 \mathrm{M}$ National Student Fellowship, an idea conceived of in 2012 by a small group of fellows and supported by $3 \mathrm{M}$ Canada and the STLHE. The ethos of the 3MNTF is alive and well among the 60 student fellows, as evidenced by the following statement in a University Affairs article written by a student fellow:

There's hope. Even though you don't take attendance, and even though there may be free videos out there on every single topic you'll ever teach us, we still come to your lectures. Maybe were crazy, or maybe were secretly wishing that you'll learn from us as well. Humans are taught best by other humans-so please, professor - educate us on the many ways that you are one.

Today, there are more than 50 news articles from media outlets across the country featuring student fellows in addition to the following outputs generated by the student fellows themselves: four reflective pieces in the peer-reviewed journal Collected Essays on Learning and Teaching; a compendium of articles on learning in the 21 st century in University Affairs written by the 2014 cohort; a collection of articles critically examining academia's "obsession with being busy" curated by the 2013 cohort; five individual projects on topics such as inclusivity, mental health, and student leadership by the 2012 cohort; and numerous presentations at national and international teaching and learning conferences.

\section{DISCUSSION}

An analysis of program artefacts corroborated with data from 11 in-depth key informant interviews revealed evidence of a program with a rich history that is characterized by a community of outstanding teachers and educational leaders. These individuals care deeply about their cause, and arein many ways, and in many places - actively championing excellence in teaching and learning in higher education at all levels: individual (micro), departmental (meso), institutional (macro), and national/international (mega). The unique attributes that constitute the character of this fellowship are associated with excellence and speak to a cultural history rich with stories and artefacts that suggests impact at many different levels.

The impact of the fellowship program begins with its role in fellows' personal and professional lives. As fellows described in their interviews, the award is one that is deeply transformative at the individual level. Consistent with Baxter Magolda's (2007) theory of self-authorship, the 3MNTF offers a developmental experience that allows fellows to grow in multiple ways. This includes the ways in which they view themselves as both practitioners of their discipline and as teachers. The retreat is considered to be a transformative element of the program through which fellows are able to share in the process of learning from and with their peers, often leading to collaborative projects. This learning not only is beneficial for fellows' teaching practice, but it also gives them the confidence to use their strengths in leveraging their leadership capacity.

62 Acai, A., Ahmad, A., Fenton, N., Graystone, L., Phillips, K., Smith, R., \& Stockley, D. (2018). The 3M National Teaching Fellowship: A high-impact community of practice in higher education. Teaching \& Learning Inquiry, 6(2). http://dx.doi.org/10.20343/teachlearninqu.6.2.5 
The fellowship also provides an opportunity for fellows to serve as educational leaders both within and outside of their institutions. The fellows profiled in various program artefacts and interviewed in this study are examples of the type of local-level leaders described by Mårtensson and Roxå (2015). As a result of their award, fellows are often asked to inform important initiatives related to teaching and learning and to serve in senior leadership positions that promote teaching and learning at the institutional level. These include traditional department and faculty leadership positions, as well as positions such as directors of teaching and learning centres and vice provosts of teaching and learning. Such positions help to directly advance the cause of teaching and learning in higher education institutions across Canada, and in some cases, even internationally.

At the heart of the 3MNTF program's impact, however, is its ability to facilitate meaningful conversations about teaching and learning. These conversations are the means to further enrich the art of teaching, fostering deep and meaningful learning — and provide an important, complementary perspective to the substantial media attention received by other university priorities, including research intensity. As one fellow explained, the essence of the fellowship lies in "the breaking down of paradigms and individuals who rise above the paradigms ... [and] a commitment and an essence of believing that .. . being teachers is one of the most important things that we can do." This ethos creates an alternate discourse for higher education-one that aims to move beyond transactional classroom strategies toward a "greater purpose" for higher education. This emphasizes universities' role as teaching institutions and suggests that this is something we should be proud of.

The sense of community that is evident when examining the culture of the fellowship is particularly important in helping to facilitate and sustain a spotlight on the importance of continuously improving and rewarding excellence in teaching and educational leadership. If there were only a few fellows, or if these were monetary awards, they would likely have an expiry date with little impact, as has been the case in other, now defunct national award programs. Moreover, it would be very difficult to challenge a culture in which teaching is valued to a lesser degree than a university's research enterprise. However, building a significant network of fellows and numerous mechanisms by which relationships are strengthened and sustained, such as the retreat and the $3 \mathrm{M}$ Council create a community of practice fellows can rely upon to gain new insights into their teaching and leadership practices (Wenger, 1998). Moreover, in cases where fellows' leadership efforts are met with challenges relating to the organizational culture at their own institutions, they can find support in a network of academics across the country and overseas who share the same deep commitment to the cause of teaching and learning in higher education that they have. In this sense, the fellowship program represents an academic microculture that challenges traditional paradigms in higher education and elevates the status of teaching and learning to the institutional, national, and international levels.

\section{LIMITATIONS AND FUTURE DIRECTIONS}

Although the program artefacts we analyzed in this study provide evidence of the program's impact beyond the positive testimonials from key informants, our study is limited in that our sample included only those intimately familiar with the fellowship program. The meanings our key informants ascribed to various program artefacts and their perspectives on the program's culture and history are likely to differ from that of other fellows, particularly those who did not continue their involvement with the program after having received their fellowship. We acknowledge that positive perceptions of impact 
are likely the result of "insider" perspectives shared by the participants in our study, a reflection of their more complete knowledge of and involvement with the program, and may not be shared by the vast majority of fellows. Thus, we recommend that future research explore the opinions of fellows who have chosen not to be so actively involved with the program. Furthermore, the $3 \mathrm{MNTF}$ program appears to struggle with the challenge of engaging colleagues at their home institutions to reveal their dispositions with respect to the ethos of the fellowship as articulated in this article. Future research might explore ways of how the fellowship program could address this challenge, considering the program does not engender a simple acceptance of these attitudes. We also encourage future researchers to consider the impact of the program from a broader perspective, perhaps seeking to examine the opinions of individuals outside of the fellowship program (e.g., Ahmad et al., 2017) or using other theoretical frameworks to examine impact (e.g., Guskey, 2002; Hart, Diercks-O’Brien, \& Powell, 2009; Kirkpatrick, 1994).

\section{CONCLUDING REMARKS}

In this study, we examined the impact of Canada's national teaching fellowship program, which equally recognizes excellence in both teaching and educational leadership. Through the analysis of a large collection of program artefacts corroborated with in-depth interviews with 11 fellows (key informants), this study reveals the 3MNTF program's impact at the individual (micro), departmental (meso), institutional (macro), and national/international (mega) levels.

The 3 MNTF program is about building community through meaningful conversations about teaching and learning. From the outset, it unites excellent teachers and educational leaders who share similar passions and creates a strong bond through the central mechanism of a retreat, which can be understood as a developmental learning opportunity that enables the formation of new ideas and inspires confidence in fellows' abilities through free-flowing conversation and dialogue. The award is also a gateway for educational leadership in that it is highly regarded by institutions as fellows are often given positions in which they can grow their leadership capacity and continue to influence positive change in their home institutions and beyond.

Perhaps the most impactful aspect of the program is the discourse it generates about the importance of universities' central mandate as institutions of teaching and learning, which has resulted in calls for action to improve the student learning experience. Recognizing that this is of central importance to the core functioning of higher education institutions yet is often not given the attention it deserves, the fellowship program has engaged faculty, administration, and students, as well as the communities they engage with, in conversations that matter at multiple levels. Taken together, this suggests that the initial vision of the fellowship program continues to be realized and that the program has played a critical role in advancing the cause of teaching and learning over its rich history of more than 30 years.

\section{ACKNOWLEDEGMENTS}

Funding for this work was provided by $3 \mathrm{M}$ Canada as part of a larger grant to study the impact of the 3M National Teaching Fellowship program.

We are grateful to the fellows who so willingly shared their thoughts and experiences about the 3MNTF program with us. Our sincere thanks also go to Torgny Roxå, for his advice on the theoretical underpinnings of this work; Sylvia Avery, for her insight into the historical aspects of the 3MNTF 
program; Michelle Ogrodnik, for her support and insight in the early stages of this work; and Robyn Routly, for her assistance with transcription.

Anita Acai is a PhD candidate at McMaster University, Hamilton, Ontario, Canada, and student scholar at the Paul R. MacPherson Institute for Leadership, Innovation \& Excellence in Teaching. She maintains active research interests in health professions education, the Scholarship of Teaching and Learning, and issues related to gender equity and work-life integration in higher education.

Arshad Ahmad is vice-chancellor at the Lahore University of Management Sciences, Lahore, Punjab, Pakistan. He was formerly viceprovost, teaching and learning and director of the Paul R. MacPherson Institute for Leadership, Innovation \& Excellence in Teaching, at McMaster University, Hamilton, Ontario, Canada. He is also the former president of the Society for Teaching and Learning in Higher Education.

Nancy Fenton is an educational developer at the Paul R. MacPherson Institute for Leadership, Innovation \& Excellence in Teaching at McMaster University, Hamilton, Ontario, Canada, and holds an assistant clinical professor position in the Faculty of Health Sciences at McMaster. She is a qualitative researcher interested in critical methodologies and has published and worked in both higher education and health.

Leah Graystone's MSc research [at McMaster University in Canada] focused on the relationship between the legislative environment (Sabrina's Law) and the everyday experiences of students with anaphylaxis. She has experience in a range of fields, including public health, education, and business. She is presently working as the coordinator for events and highly qualified personnel at AllerGen NCE Inc.

Keegan Phillips was an MSc student at McMaster University, Hamilton, Ontario, Canada, and research assistant at the Paul $R$. MacPherson Institute for Leadership, Innovation \& Excellence at the time of this study. His research interests include public health, epidemiology, and study design.

Ron Smith is professor emeritus of education at Concordia University, Montréal, Québec, Canada, and past chair of the $3 M$ Council of National Teaching Fellows. He directed Concordia's Centre for Teaching and Learning Services for 24 years.

Denise Stockley is professor and scholar in higher education with the Office of the Provost, seconded to the Faculty of Health Sciences, and cross-appointed to the Faculty of Education at Queen's University, Kingston, Ontario, Canada. She is the current president of the Society for Teaching and Learning in Higher Education.

\section{NOTES}

1. From 1986 to 2016, the $3 \mathrm{M}$ National Teaching Fellowship was awarded only to teachers at Canadian universities. However, beginning in 2017, the award was extended to all teachers at Canadian institutions of higher education, including those at community colleges.

\section{REFERENCES}

Ahmad, A., Fenton, N., Graystone, L., Acai, A., Matthews, K. E., \& Chalmers, D. (2018). Investigating Impact in Higher Education. Hammondville: Higher Education Research and Development Society of Australasia.

Ahmad, A., Stockley, D., \& Moore, R. (2013). 3M fellows making a mark in Canadian higher education. In D. J. Salter (Ed.), Cases on quality teaching practices in higher education (pp. 182-190). Hershey: IGI Global.

Ahmad, A., Stockley, D., Smith, R., \& Hastings Truelove, A. (2017). The 3M National Teaching Fellowship: Findings from a national questionnaire on the impact of the program. Collected Essays on Learning and Teaching, 10, 15-26.https://doi.org/10.22329/celt.v10i0.4744

Barbour, R. S. (2001). Checklists for improving rigour in qualitative research: A case of the tail wagging the dog? BMJ, 322(7294), 1115-1117.https://doi.org/10.1136/bmj.322.7294.1115 
Baxter Magolda, M. B. (2007). Self-authorship: The foundation for twenty-first century education. New Directions for Teaching \& Learning, 2007(109), 69-83. https://doi.org/10.1002/tl.266

Graham, R. (2012). Achieving excellence in engineering education: The ingredients of successful change. London: Royal Academy of Engineering. Retrieved from https://www.raeng.org.uk/publications/reports/achieving-excellence-in-engineering-education.pdf

Guskey, T. R. (2002). Professional development and teacher change. Teachers and Teaching: Theory and Practice, 8(3/4), 381-391.https://doi.org/10.1080/135406002100000512

Hannah, S. T., \& Lester, P. B. (2009). Multilevel approach to building and leading learning organizations. Leadership Quarterly, 20(1), 34-48. https://doi.org/10.1016/j.leaqua.2008.11.003

Hart, D., Diercks-O'Brien, G., \& Powell, A. (2009). Exploring stakeholder engagement in impact evaluation planning in educational development work. Evaluation, 15(3), 285306. https://doi.org/10.1177/1356389009105882

Kirkpatrick, D. L. (1994). Evaluating Training Programs: The Four Levels. Oakland: Berrett-Koehler Publishers.

Macfarlane, B. (2011). Professors as intellectual leaders: Formation, identity and role. Studies in Higher Education, 36(1), 57-73.https://doi.org/10.1080/03075070903443734

Mårtensson, K., \& Roxå, T. (2015). Leadership at a local level-Enhancing educational development. Educational Management Administration \& Leadership, 44(2), 247-262.https://doi.org/10.1177/1741143214549977

Miles, M. B., \& Huberman, A. M. (1994). Qualitative Data Analysis (2nd ed.). Thousand Oaks: Sage.

Schein, E. H. (2004). Organizational Culture and Leadership (3rd ed.). San Francisco: Jossey-Bass.

Simmons, N. (2016). Synthesizing SoTL institutional initiatives toward national impact. New Directions for Teaching \& Learning, 2016(146), 95-102. https://doi.org/10.1002/tl.20192

Smith, R., Stockley, D., Ahmad, A., Hastings, A., Kinderman, L., \& Gauthier, L. (2017). Perspectives on the impact of the $3 \mathrm{M}$ National Teaching Fellowship program. Innovations in Education and Teaching International, 54(4), 386-393.https://doi.org/10.1080/14703297.2016.1255154

Society for Teaching and Learning in Higher Education (STLHE). (n.d.). 3M National Teaching Fellowship. Retrieved from https://www.stlhe.ca/awards/3m-national-teaching-fellowships/

Streatfield, D., \& Markless, S. (2009). What is impact assessment and why is it important? Performance Measurement and Metrics, 10(2), 134-141. https://doi.org/10.1108/14678040911005473

Wenger, E. (1998). Communities of practice: Learning, Meaning, and Identity. New York: Cambridge University Press.

Yukl, G. A. (2002). Leadership in Organizations (5th ed.). Upper Saddle River: Prentice-Hall.

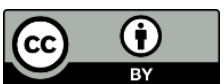

Copyright for the content of articles published in Teaching \& Learning Inquiry resides with the authors, and copyright for the publication layout resides with the journal. These copyright holders have agreed that this article should be available on open access under a Creative Commons Attribution License 4.0 International (https://creativecommons.org/licenses/by/4.0). The only constraint on reproduction and distribution, and the only role for copyright in this domain, should be to give authors control over the integrity of their work and the right to be properly acknowledged and cited, and to cite Teaching \& Learning Inquiry as the original place of publication. Readers are free to share these materials — as long as appropriate credit is given, a link to the license is provided, and any changes are indicated. 